\title{
Interactive Digital Textbook Development Methodology for Higher Education
}

\author{
Kwang Sik Chung ${ }^{* 1}$, Hye Won Byun ${ }^{\# 2}$, Sungsuk Kim ${ }^{\# 3}$, Heon Chang Yu ${ }^{\# 4}$ \\ ${ }^{* 1}$ Dept. of Computer Science, Korea National Open University, Jongno-ku, Dongsung-dongs, Seoul, 110-791, Korea \\ E-mail: kchung0825@knou.ac.kr \\ ${ }^{\# 2}$ Dept. of English Language and Literature General English Program, Sejong University, Gwangjin-gu, 209 Neungdong-ro, Seoul, 143-747, \\ Korea \\ E-mail:wonnyb@sejong.ac.kr \\ ${ }^{\# 3}$ Dept. of Computer Science, Seokyeong University, 124 Seogyeong-ro Seongbuk-gu Seoul, 02173 Korea, \\ E-mail:sskim03@skuniv.ac.kr \\ ${ }^{\# 4}$ Dept. of Computer Science Education, Korea University, 02841145 Anam-ro, Seongbuk-gu, Seoul, 02841, Korea, \\ E-mail: yuhc@korea.ac.kr
}

\begin{abstract}
As multimedia based distance learning and sensor-based ICT services gets popular and developed, students need unified learning environments that can provide one-stop learning contents access service with mobile devices. On the one-stop learning environments, students can access learning multimedia, digitized textbook, Q\&A, references, and virtual experiment learning contents with only one educational device. The learners increasingly desire the virtual experiment learning contents with frequent interaction between students and learning contents. Thus, a methodology for digital textbook development with virtual experiment learning interactions should be standardized and developed. This study is on the desirable development plan of digital textbook under the virtual experiment e-learning contents and textbooks for the distance educational circumstance. The objective of this study is to propose a virtual experiment digital textbook development methodology to develop the digital textbook which unifies on virtual experiments learning contents, assessment Q\&A, small-size examinations, printed educational materials (etc. textbook) and cuttingedge multimedia learning contents simultaneously, and activates various virtual experiment learning interactions of students. For this reason, we have developed the specialized methodology by analyzing the KNOU (Korea National Open University) digital textbook development methodology and e-learning contents for experiment subjects (chemistry, nursery, agricultures, etc.). Proposed digital textbook development methodology has been designed to provide an interactive learning environment that stimulates students to focus on learning environments such as simulation multimedia contents, lecture notes, digitized textbook, virtual experiments contents, and assessment Q\&A. This study develops the digital textbook application of the chemistry subject for the freshman and surveys the students' feasibility of the digital textbook application.
\end{abstract}

Keywords - Digital textbook; virtual experiments; learning contents design; learning interactions design

\section{INTRODUCTION}

On-line learning contents and services have been rapidly developed along with the development of communication technology and sensors technology. Due to its various advantage over existing off-line learning environments, Online learning contents and services were spread among various learning fields to train and educate various kinds of students. Especially, 'Virtual Laboratory' intends to realize the objective of delivering virtual experiments environment through various interactions and sensors. The virtual experiments learning contents with digital textbook were designed to simulate the actual experiments practices environments. With digital textbook combined with virtual experiments practice learning contents, learners can easily experience chemistry experiments, watch the learning video, and confirm their knowledge. Especially the capacity of experiments is limited by the constraints of space, hazards of carelessly handling tools and materials, and the lack of proper safety education.

Nevertheless, delivering virtual laboratory contents with a digital textbook can be highly effective regarding improving pedagogical outcomes. Although the effects have been known, a development methodology for virtual experiments digital textbook dealing with experimental contents has not yet been developed. Thus, we proposed the development methodology for virtual experiments digital textbook and 
developed prototype of the virtual experiments digital textbook. We have taken learner's learning interaction seriously with the learning contents to enable learners to experience learning experience with the virtual experiments digital textbook.

Printed textbooks are composed of texts and images that are designed by the instructors. The printed textbooks, however, are only used as tools of interaction between the learners and the teacher. It means that the learning contents on printed textbooks are not movable, touchable, editable, and addable. Digital textbook, on the other hand, not only have the roles of the previously printed textbooks, but they are also able to utilize interactions between the learners and learning contents, or between the teachers [1] - [4]. In order to utilize interactions of the multimedia on a digital textbook, interaction utilization strategy should be considered at the first design stage. Previous digital textbook were considered as compliment reference for traditional teacher-learner models and business model [5] - [9]. However, with sensors on smart devices, new interactions can be implemented and should be put into the design and strategy of a digital textbook. Also, some scholars proposed the interactive digital textbook and developed their product methods [10], [11] and others proposed the ICT technology usage methods [11]. However, there was no methodology for digital textbook development [12]. Recently, only contents development method was available [13], and we proposed contents and sensor access development method. Procedural content generation framework is proposed [14], and this framework could be useful for interactive learning contents design and methodology.

\section{MATERIAL AND METHOD}

The developing stages and the product to be created are described as in Figure 1. Sensors development stage and checkpoints are added to digital textbook development stage [9].

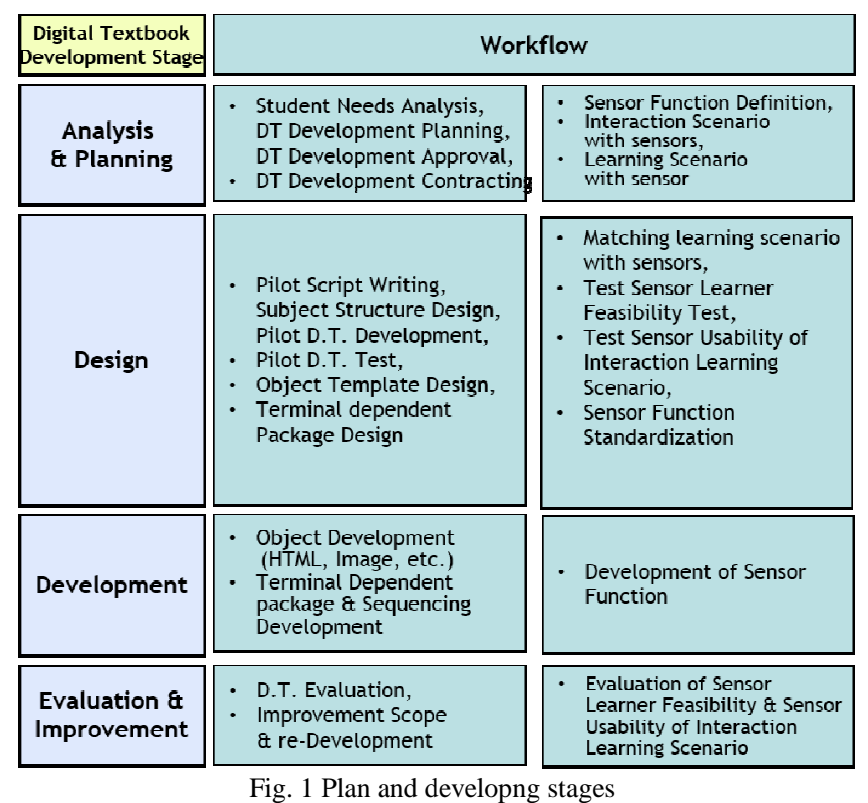

In Plan and Analysis Stage, instructors and developers define sensor function definition, interaction scenarios with sensors and learning scenarios with the sensor. Especially sensors embedded with smartphones should be confirmed. In Design Stage, with matching learning scenario with sensors, developers design sensor test, learner feasibility test and sensor usability test of interactive learning scenario, and sensor function standardization. In Development and Implementation Stage, sensor functions are implemented and adapted into a digital textbook. Sensor learner feasibility and sensor usability of interactive learning scenario is evaluated and maintained.

\section{A. Checklists of the digital textbook development}

1) Plan and Analysis Stage: The analysis and planning stage of digital textbook comes from an analysis of the planning stage of the traditional textbook and planning stage of the e-learning contents. At the analysis and planning stage of digital textbook, learner interaction requirements for digital textbook are analyzed, and the interaction requirements between digital textbook and learners are defined. Instructors and developers of a digital textbook, interaction designs, implementation strategy, decide sensors usage methods and sensors function definitions for interaction. Learning Contents and Goal based on Learning Interaction are defined and digital textbook learning scenarios are constructed.

- Digital textbook Development Planning

- Analysis of learner interaction requirements

- Analysis of Interaction Requirements

- Experiment \& Practice Course Interaction Feasibility Analysis

- Interaction Feasibility Analysis between Sensor function of Digital textbook \& Experiments and Practice

- Learning Scenario Definition for Experiments and Practice Interaction

- Learning Supports Methods Definition for Experiments and Practice Interaction

- Digital textbook Design Planning

- Interaction classification definition between learners and Digital textbook

- Interaction definition between learners and Digital textbook

- Digital textbook Planning Meeting

- Learning Contents and Goal based on Learning Interaction

- Requirements Definition of Learners and Instructors

- Sensor and Interaction Association Analysis and Usage Strategy Construction

- Establishment of Interaction Instruction Design strategy

- Instructor and Developer Workshop

- Discussion for interaction design and implementation strategy

- Sensors usage methods and sensors function definitions for interaction

- Previous sensors usage methods and function definitions analysis

2) Design Stage: In the design stage, the author prepares the sample manuscripts of the raw learning instruction and manuscripts. The designers and instructors design the sample 
manuscript according to the characteristics of interaction instructions and the subject with the sample manuscript received from the textbook author and professor. After the structural learning design, pilot contents are developed and tested, and the development of the template and the design of the package for each terminal are performed.

- Subject Instructional Design

- Instruction design strategy (micro design)

- UI/UX design and instruction design for interaction between sensors and experiment and practice learning contents

- Interaction learning scenario design

- Storyboard design for interaction scenario

- Prototype Development

- Implementation of Sample interaction scenario prototype

- Implementation of sample interaction support scenario prototype

- Storyboard prototype implementation for interaction scenario

- A digital textbook prototype implementation

- UI/UX prototype implementation

- Learning device function definitions

3) Development and Implementation Stage: In the development stage, developers develop and implement the entire Digital textbook based on interactive learning-based learning scenarios, interaction design of learner-digital textbook contents, interactive teaching design of sensors and Experiment \& Practice Interaction learning contents, and UI/UX design. In particular, we will standardize the interaction types and the use of sensors for various Experiment \& Practice Interactions that occur during the development of Digital textbook.

The digital textbook is developed so that interactive learning activities can be diversified and Digital textbook enables self-directed learning. In particular, considering the range of relevant interactions according to the characteristics of the smart devices, the package, and modularization for each smart terminal should be considered.

- The digital textbook Function implementation

- Development of digital textbook according to experiment \& practice digital textbook design strategy and writing manuals

- Development of sensor function for interaction strategy

- Digital textbook Development

- Development of digital textbook framework and interaction learning contents

- Development of video and audio learning contents

4) Evaluation and maintenance stage: At the evaluation and maintenance stage, students will use and test a digital textbook, find functional errors and review and evaluate the contents. From the review results, instructors and developers improve the interaction scenarios and digital textbook contents.

- Digital textbook Deployment and Inspection

- Experiment \& Practice learning contents installation on Digital textbook

- Evaluation

- Learning contents metadata standards adaptation tests

- Learning device package standards adaptation tests
- Development stage Quality evaluation

- Learners and instructor feasibility test

- Maintenance

- Errors correctness and maintenance

- A new strategy for feasibility and functional improvement

\section{B. Tasks of the digital textbook development methodology}

1) Plan and Analysis Stage: In the planning and analysis stage, learning objectives and contents based on curriculum, learner and instructor, learning environment, technical trends of hardware and software related to digital textbook development, and related teaching-learning theory should be analyzed.

- Digital textbook Development Planning

- analyzing the requirements of the interaction with the learner and digital textbook

- constructing experiments \& practice digital textbook Development planning

- Experiment \& Practice Interaction Feasibility Analysis

- analyzing the interoperability suitability of sensor functions and experiments and practice learning contents required in the digital textbook by digital textbook developers and learning content designers

- determining the scope of learning scenarios based on Experiment and practice interaction learning content designers

- determining the scope of sensor-based learning activities design by the digital textbook developer

- Digital textbook Interaction Design

- defining the types and classifications of interactions between learners and experiments \& practice learning contents in the digital textbook by instruction designer

- defining criteria for interactions between learners and experiments \& practice learning contents

- designing services and functions of experiments \& practice learning contents on digital textbook

- Planning Meeting and requirements analysis

- analyzing the characteristics of learning contents related to experiments and practice

- analyzing general characteristics and starting point behavior of learners

- constructing experiments \& practice sequences and contents structures of learning contents

- establishing instruction design strategy to satisfy learners interaction requirements

- defining utilization sensors and interaction associations

- investigating the primary sensors of interactive learning contents

- defining the type, requirement, and scope of the learning device

- Instructor \& developer Workshop

- sharing the goal of interactive experiments and practice learning contents by instructors and digital textbook developers

- sharing the purpose of experiments and practice learning contents and the technical environment of the sensors by instructors and digital textbook developers.

2) Design Stage: Based on the results of the planning and analysis stage, it is necessary to plan and organize assessment methods appropriate to the interaction strategy of 
digital textbook, design strategy of interaction activities, and characteristics of interactive learning contents. Screen presentation, UI/UX presentation, and program development strategy are designed related to this.

Based on the design content, a flowchart for learning contents and digital textbook development design is produced, and the relationship between the contents presented on each screen and the screen is created in a storyboard format.

- Prototype development

- developing prototype of sample interaction scenario, interaction support scenario and storyboard prototype for interaction scenario

- implementing a digital textbook prototype

- testing a sample interaction scenario and sample interaction learning support scenario based on the results of the interaction analysis stage and the workshop decision results

- designing and developing UI/UX developments strategy for learners

- implementing basic sensors functions

- Subject instructional design

- design of instruction strategy (micro design), interaction learning scenario and storyboard design for interaction scenario

- designing UI/UX of interaction between sensors and experiment and practice learning contents

- reviewing prototype design and learning scenario and storyboard

- constructing macro instruction design for interactions between learners and learning contents

3) Development and Implementation Stage: According to the design stage result, two or three prototype modules are selected and developed, before the all of the learning contents and interaction modules are developed. After that, the prototype modules are confirmed through the report formation evaluation process.

- The digital textbook Function implementation

- developing sensor functions for interaction and interaction functions based on Experiment \& Practice instructional design and development strategy

- implementing interaction storyboard and learning scenario

- Digital textbook Deployment and Inspection

- developing a digital textbook framework and interactive learning contents according to the interaction storyboards and interactive learning sequences

- implementing a learning scenario and digital textbook contents (audio and video) with learners' requirements

- constructing SNS connection service with other SNS (Facebook, LINE, and Instagram.)

4) Evaluation and Maintenance Stage: At the implementation and evaluation stage, learning-teaching process and scenario is planned and implemented, according to the attributes of the teaching and learning environment in which the Digital textbook are utilized, the degree of recognition of the learner's interactions, and the characteristics and reactions of learning contents and learning activities.
The evaluation of the developed digital textbook and application results can evaluate the educational effect through the learner's response to the digital textbook and the degree of academic achievement. These results are the basis for other useful applications of digital textbook and interaction learning scenario.

- Digital textbook Deployment and Inspection

- installing experiments \& practice learning contents

- developing a digital textbook framework

- porting digital textbook framework on learning contents server

- Confirming digital textbook service on Learning Management System

- evaluating interaction functions and learning contents

- delivering experiment \& practice learning contents on digital textbook

- Evaluation

- evaluating quality evaluations of Digital textbook per interaction scenario (learners, instructors, learning experts)

- confirming learning contents metadata standards adaptation

- testing learning device package standards adaptation and learners and instructors feasibility

- evaluating development stage Quality

- Maintenance

- confirming and correcting the result of the evaluation stage and requirements

- constructing a strategy for feasibility requirement

\section{RESULTS AND DISCUSSION}

\section{A. Results of learner survey}

We developed four kinds of interactions, and they use different sensors [8]. The first interaction is 'drag and drop.' A learner drags experiment apparatuses into 'dotted rectangle and drops' and combines the experiment apparatuses. After following the correct assembly sequence, a learner can confirm the correctly-assembled experiments result.

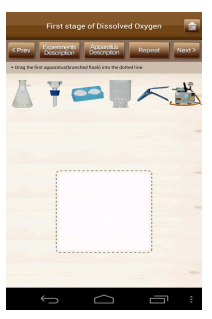

(a)

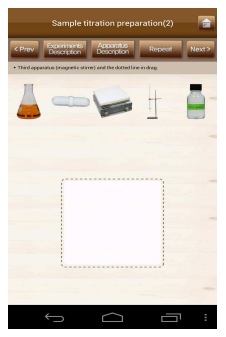

(c)

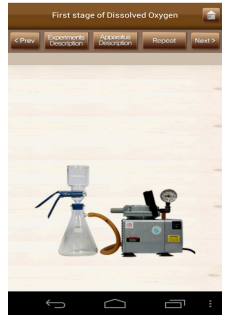

(b)

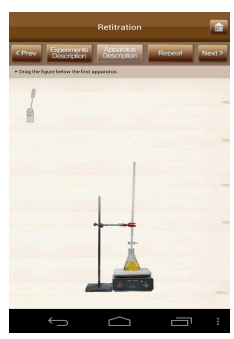

(d)
Fig. 2 'Drag and Drop' interaction 
The second interaction is 'tilting.' A learner drags an experiment apparatus into 'dotted rectangle and drops' and combines the experiment apparatuses. After following the correct assembly sequence, a learner can confirm correctly assembled experiments apparatuses result.

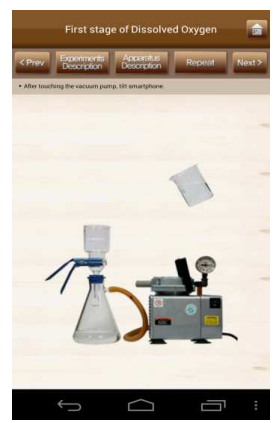

Fig. 3 'Tilting' interaction

The third interaction is 'shake.' A learner shakes a smartphone so that an experiment apparatus is shaken and a learner can confirm the experiment change result.

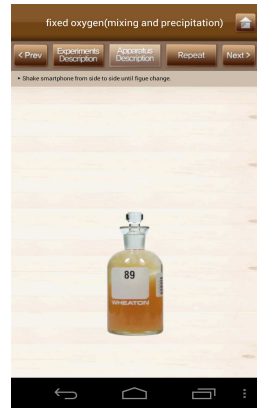

(a)

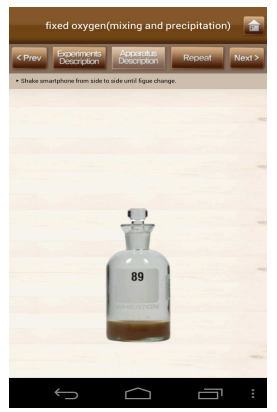

(b)
Fig. 4 'Shaking' interaction

The fourth interaction is 'switch-on.' A learner touches an experiment apparatus with touch sensor so that the experiment apparatus works and a learner can confirm the experiment change result.

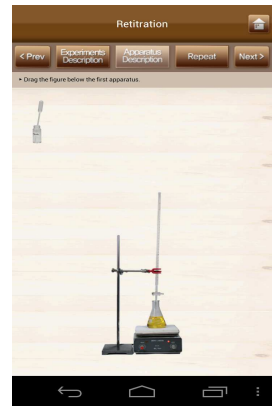

(a)

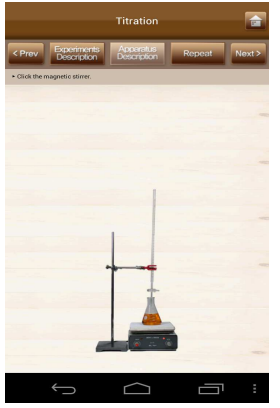

(b)
Fig.5 'Switch-on' interaction

\section{B. Discussion}

Multiple regression was analyzed in two parts. First, the overall satisfaction (q501) was examined by the overall login (q101), interface (q201), content accessibility (q301), and exercises (q401). Next, each category of the questions was examined by the sub-questions that followed the survey.
This was to examine whether the sub-questions had a significant value or correlations with each category.

Table 1 describes the questions and codes used in the analysis.

TABLE I

SURVEY QUESTIONS AND CODES

\begin{tabular}{|l|l|c|}
\hline \multicolumn{1}{|c|}{ Main Idea } & \multicolumn{1}{|c|}{ Questions } & Code \\
\hline $\begin{array}{l}\text { Overall } \\
\text { Satisfaction }\end{array}$ & $\begin{array}{l}\text { The overall virtual experiment } \\
\text { was satisfactory. }\end{array}$ & Q501 \\
\cline { 2 - 3 } & Overall menu use was easy. & Q502 \\
\cline { 2 - 3 } & $\begin{array}{l}\text { It was easy to understand the } \\
\text { experiment with this content. }\end{array}$ & Q503 \\
\cline { 2 - 3 } & $\begin{array}{l}\text { The virtual content experiment } \\
\text { will help understand the offline } \\
\text { classroom experiment. }\end{array}$ & Q504 \\
\hline
\end{tabular}

From the regression model, stepwise regression was used in all of the analysis. In stepwise regression, variables are entered into the model one at a time in order of their correlation and variables that do not add to the success of the model are excluded in the method. In addition, when predictors are no longer statistically significant, the model will reject the least statistically significant of these predictors

The first questions in each category examined overall satisfaction of the experiment. First questions in each category represented the overview of each category. The dependent variable in this analysis is the overall satisfaction of the experiment. The independent variables are the system login accessibility, interface accessibility, content accessibility, and exercise accessibility. Table 2 shows that only the overall content accessibility was able to explain the dependent variable; overall satisfaction of the experiment. This variable accounted for $23 \%$ of the variances (R2 $=.234)$.

TABLE II

STEPWISE REGRESSION MODEL SUMMARY FOR OVERALl SATISFACTION

Model Summary b
\begin{tabular}{|l|c|l|l|l|l|}
\hline & & & Adjusted R \\
Model & $\mathbf{R}$ & $\mathbf{R}$ Square & $\begin{array}{l}\text { Std. The error } \\
\text { of the Estimate }\end{array}$ & $\begin{array}{c}\text { Durbin- } \\
\text { Watson }\end{array}$ \\
1 & $.484 \mathrm{a}$ & .234 & .213 & .797 & .657 \\
\hline
\end{tabular}

a. Predictors: (Constant), Contents

b. Dependent Variable: overall satisfaction

Table 3 displays the coefficients values of the predictor or the independent variables for the overall satisfaction of the experiment. As content accessibility was the only variable significant, enough to be included in the model, the data only displays the coefficient value for this variable. Since standardized coefficients Beta value uses a standard unit as opposed to the unstandardized $\mathrm{B}$, these values will be examined. The content was the only variable (Beta $=.484 \mathrm{p}$ $=.002$ ) entered into the model, and the positive value indicates that the overall satisfaction of the experiment had a positive relationship with the contents of the experiment. 
TABLE III

STEPWISE REGRESSION ANALYSIS EXAMINING OVERALL SATISFACTION

Coefficients

\begin{tabular}{|c|c|c|c|c|c|c|}
\hline & & & $\begin{array}{l}\text { andardized } \\
\text { efficients }\end{array}$ & $\begin{array}{c}\text { Standardized } \\
\text { Coefficients }\end{array}$ & & \\
\hline & Model & B & Std. Error & Beta & $\mathbf{t}$ & Sig. \\
\hline 1 & $($ Constant $)$ & 2.080 & .489 & & 4.255 & .000 \\
\hline & Contents & .448 & .133 & .484 & 3.361 & .002 \\
\hline
\end{tabular}

a. Dependent Variable: overall satisfaction

The results indicate that overall satisfaction of the experiment can partially be predicated by whether the contents were accessible enough for the participants. Nonetheless, other factors such as the accessibility of the login system, the access interface of the system or the accessibility of the exercise included in this experiment were not able to explain or predict the overall satisfaction for the users.

\section{CONCLUSION}

Since there was a limitation of devices such as the keyboard and the mouse, previous e-learning contents were only able to utilize the one-way interaction between the learning contents and the learners. These kinds of one-way interactions and contents, however, were not able to take the real learning laboratory experience into the contents, let alone achieve the learner-center learning environment. Using only the mouse and keyboard not only create a passive learning environment, but it also decreases the level of concentration and interest, while real-life laboratory learning is all learner-centered and encourages learner participation.

Therefore, but we have also tried to make a new learning environment for engineering/natural science-majored learners. First, virtual interaction learning contents with digital textbook were proposed, and the interactive digital textbook using smartphone sensors and methodology of an interactive digital textbook for experimental subjects were developed. Developing digital textbook with interactions should fully take consideration of the relationship between the various interactions and learning efficiency. We will measure the relationship and efficiency of learning interactions and learning activities.

\section{REFERENCES}

[1] K. Chung, "Learning Reaction Analysis Engine for Interactive Digital Textbook Platform," Advanced Multimedia and Ubiquitous Engineering pp 459-465, 2017

[2] K. Chung, et al., "Design and Development of Sensor-based Virtual Experiment Contents for Smart Phone," Chungbuk Journal of Education 2007. Vol 28 No. 1., pp. 39-69, 2007.

[3] B. Son,1 et al., "A Study on the Case of Domestic and Foreign Etextbooks," Korea Education \& Research Information Service. RR 2004-5, 2004.

[4] Y. Jung, et al., "A Study on the Standardization (Methods) of Digital textbooks," Korean Educational Development Institute. CR-2008, 2008 .

[5] K. Son, A. Han, "Design and Development of e-Learning Contents Authoring System based on e-Learning Environment," The Journal of Educational Information and Media, Vol 12(4), pp.77-104, 2006.

[6] S. Ku, K. Youn, "A Study of Textbook System Models of KNOU," Korea National Open University, Institute of Distance Education. 0606, pp.6-31, 2007.

[7] Kwang sik Chung, et al., "Studies Suspension Prevention System of the Distance Learning Using Cloud and Big Data," 2017 Parallel Conferences of AR4MET-ICOED-REEGETECH, 2017

[8] Kwang Sik Chung, Sooyoul Kwon, Wen-Hao Huang, "Design and Development of Sensor-based Virtual Experiment Contents for Smart Phone," Journal of Digital Contents Society 2013, Volume 14, Issue 2 , pp.161-169, 2013.

[9] Kwang Sik Chung, Joo Hee Kim, Joo Hee Choi, Hye Won Byun, Study on the Digital textbook Business Model of KNOU press, Proceeding of AAOU 2010, October 26 - 28, 2010.

[10] Shin-nosuke Suzuki, Yutaro Akimoto, Manabu Ishihara, Yukio Kobayashi, "Basic Development of the Active Textbook System consisted of a General book and a Portable Electronic Terminal,' Procedia Computer Science, 2017, Volume 112, pp. 109-116, 2017.

[11] Christian Bokhove, "Using Technology for Digital Mathematics Textbooks: More than the Sum of the Parts," The International Journal for Technology in Mathematics Education, Vol. 24, Iss. 3, pp. 107114, 2017.

[12] Jeong Yong Ahn, Kyung-Soo Han, Jae Gyu Jeon, Designing a digital textbook for the classroom in the Mobile age" Multidisciplinary Academic Conference 2017, pp. 402-406, 2017.

[13] Yasung Park, Yong Kim, "A Design and Development of microLearning Content in e-Learning System," International Journal on Advanced Science, Engineering and Information Technology, Vol. 8 No. 1, pp. 56-61, 2018

[14] Danial Hooshyar, Moslem Yousefi, Heuiseok Lim, "A Procedural Content Generation-based Framework for Educational Games: Toward a tailored data-driven game for developing early English reading skills." Journal of Educational Computing Research, 